\title{
The Beliefs of Local Communities towards the Conservation of Birds
}

\author{
Jairus Nyongesa Koki ${ }^{1 *}$ \\ ${ }^{1}$ Tourism and Hospitality Department, School of Business and Economics, Jaramogi Oginga Odinga University of Science and \\ Technology, P.O.Box 210-60401, Bondo, Kenya
}

Received 14 December 2020; Revised 12 February 2021; Accepted 21 February 2021; Published 01 March 2021

\begin{abstract}
The community guide beliefs attached to different birds provides a practical index of the diversity and condition of an ecosystem on a site-by-site basis using birds as indicators. It is believed that protecting and managing such sites will result in the conservation of some of the most sensitive, fragile, and ecologically rich habitats in the world. However, acceptance of the community-guided beliefs concept and, thus, site conservation action by local communities is dependent on their perception of the importance of birds with regard to some aspects of their livelihood. The study was undertaken to examine the community guide beliefs attached to different birds in Kenya within the Maasai, Nyanza, Western, Rift Valley, and Coastal regions. Results obtained from a Google form questionnaire survey suggest that the response with a high proportion was from a Western community or locality where people lived.
\end{abstract}

Keywords: Community; Birds; Cultural Beliefs; Avitourism; Biodiversity and Conservation.

\section{Introduction}

Birds play a significant role in the lives of people across virtually all communities and continents. In most communities, significant beliefs have developed in relation to birds, usually as a result of direct and regular contact with specific bird species, especially in cases where such birds possess prominent visual, auditory, or behavioral characteristics. In turn, these beliefs, which are usually constructed through a process of social interaction, give rise to a variety of practices and behaviors that center around these bird species [1-3]. These practices and behaviours range from actual uses, such as making use of birds for more symbolic purposes, as is the case in art such as painting, dancing, or sculpture. The consequences of these beliefs could vary from being inimical and destructive to the species, to being of no consequence or even to having a protective influence on the conservation of the species [4-7]. Conversely, traditional beliefs may also lead to the protection of certain species by specific cultures in the form of food taboos.

The bird historically occurred in all southern and east-African countries south of the equator, from the southern parts of Kenya, all the way down to South Africa and west into Uganda, Rwanda, Burundi, the Democratic Republic of the Congo, and Angola [8-12]. The species' conservation status is affected by biological factors [13, 14]. In addition to these biological factors, the species has now disappeared from large parts of its historical range and is mainly restricted to protected areas, probably as a result of such anthropogenic threats as habitat destruction, direct

\footnotetext{
* Corresponding author: mbuotisampson@gmail.com

doi http://dx.doi.org/10. 28991/HEF-2021-02-01-04

$>$ This is an open access article under the CC-BY license (https://creativecommons.org/licenses/by/4.0/).

(c) Authors retain all copyrights.
} 
persecution, indirect poisoning, electrocution, trade in live specimens, and use in traditional cultural practices. A number of hornbill species are used in cultural practices, particularly in Asia. However, only a small number of studies have recorded beliefs and practices in the northern parts of the SGH's range [15], most notably in Tanzania and Kenya, where these beliefs also relate to their social and spiritual worlds. However, a major gap exists in documented knowledge about the beliefs and practices related to the SGH's use in Rwanda, Burundi, Zambia, the Democratic Republic of the Congo, Angola, Namibia, and Botswana. Furthermore, most of the published records on this topic seem outdated and/or anecdotal. From an ethno-ornithological perspective [16-18], it is important to document the beliefs and practices related to the SGH, not only because it forms part of the African cultural heritage but also because such knowledge could potentially contribute to conservation efforts in a variety of different ways as a result of an enhanced understanding of the dynamics of humans.

\section{Materials and Methods}

\subsection{Study Setting}

The study was carried out in Maasai community, Coastal region community, Rift-Valley community, and Western community and Nyanza community in Kenya (Figure 1).

\subsection{Study Participants}

Maasai, Coastal region, Rift-Valley, Western and Nyanza communities in Kenya both male and females aged between 21 years and above, who were community guides were selected for the study.
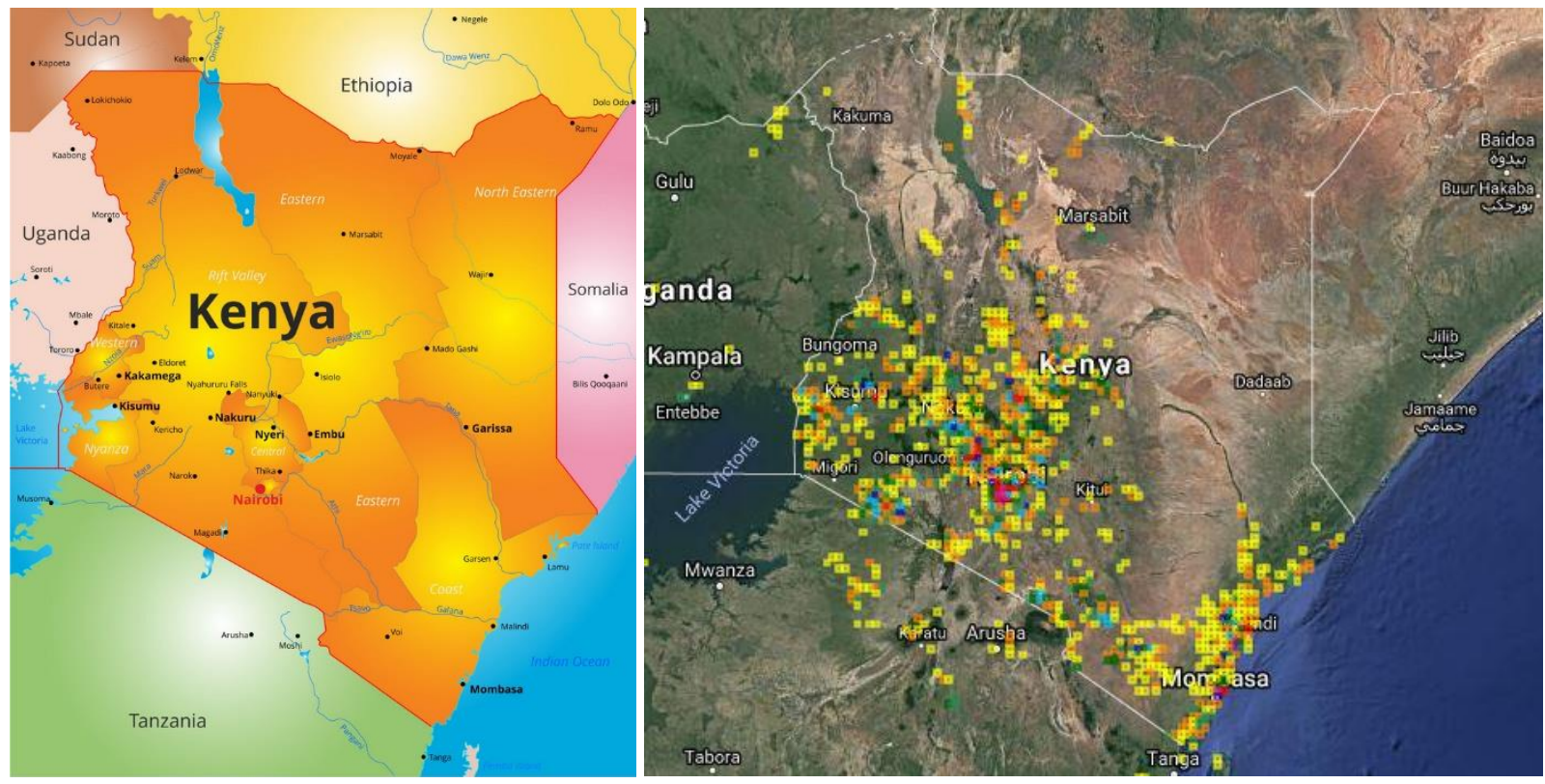

Figure 1. Kenya Bird Map Project [19]

\subsection{Sample-size and Sampling Design}

Considering the prevalence of community guides beliefs attached to different birds in Kenya located within Maasai, Coastal region, Rift-Valley, Western and Nyanza communities, the sample-size came to be 37 . According to Taylor et al. (2018) [20], descriptive technique, and descriptive statistics were applied to carry out analyze responses. Furthermore, descriptive technique enables to analyze data obtained throughout google sheet questionnaire. Research design implemented for this study. Researcher applies survey research-design via google sheet to obtain primary-data. Qualitative technique, enables to obtain comprehensive data about prevalence of community guides beliefs attached to different birds in Kenya.

\subsection{Study Instruments Used}

A predesigned, pretested, semi-structured google form questionnaire was used for collecting socioeconomic details and information regarding community guides beliefs attached to different birds in Kenya. Socioeconomic details mainly comprised data on subject's age, gender and area of residence. Google form questionnaire was used for obtaining information about community guides beliefs attached to different birds in Kenya. The community guides beliefs attached to different birds in Kenya was recorded as reported by the study participants. 


\subsection{Data Collection}

The google form questionnaire was used as the data collecting tool. The responses were discussed and modified to ensure standardization. Participants were provided with the information sheet in English language and they were explained about the study, its objective, procedure, and their rights. The participants refusing to participate were categorized as 'non-respondents'. The study was conducted in compliance with 'Ethical Principles and confidentiality of each participant was ensured. The researcher shared his identity with the participants.

\subsection{Data Analysis}

Researcher applies frequencies, and percentages, to perform analysis, and to get vital facts about community guides beliefs attached to different birds in Kenya. Qualitative tools, such as charts, and tables, enables to analyze data effectively and leads to obtain valuable facts. As well, averages, and percentages, facilitates to investigate data successfully and leads to obtain valuable realities about community guides beliefs attached to different birds in Kenya. Data was entered in SPSS (version 25) for statistical analysis. Wherever applicable, proportion, descriptive statistics and custom tables were generated.

\section{Results}

A total of 37 community guides in Maasai, Nyanza, Western, Rift Valley and Coastal communities in Kenya were eligible for the study. Thus, the response rate in the present study was $100 \%$.

\section{Sociodemographic Profiles}

The sociodemographic profiles of the study participants are shown in section A. $29.7 \%$ of the respondents were above 35 years Most of the respondents were male (68\%). Majority of the community guides had their education up to university level that is $54.1 \%$. Most respondents (30\%) were from western community.

\subsection{Section A: Key Sociodemographic Profile of the Respondents $(n=37)$}

From the findings in, $68 \%$ of the respondents were male while $27 \%$ of the respondents were female and the nonresponse was $5 \%$. This indicates the findings was gender biased. Since a larger proportion of male respondent to the google form questionnaire as compared to the female. The study findings revealed that Avitourism and biodiversity of birds habitat conservation was highly promoted and marketed by male tour guides in the community (Figure 2).

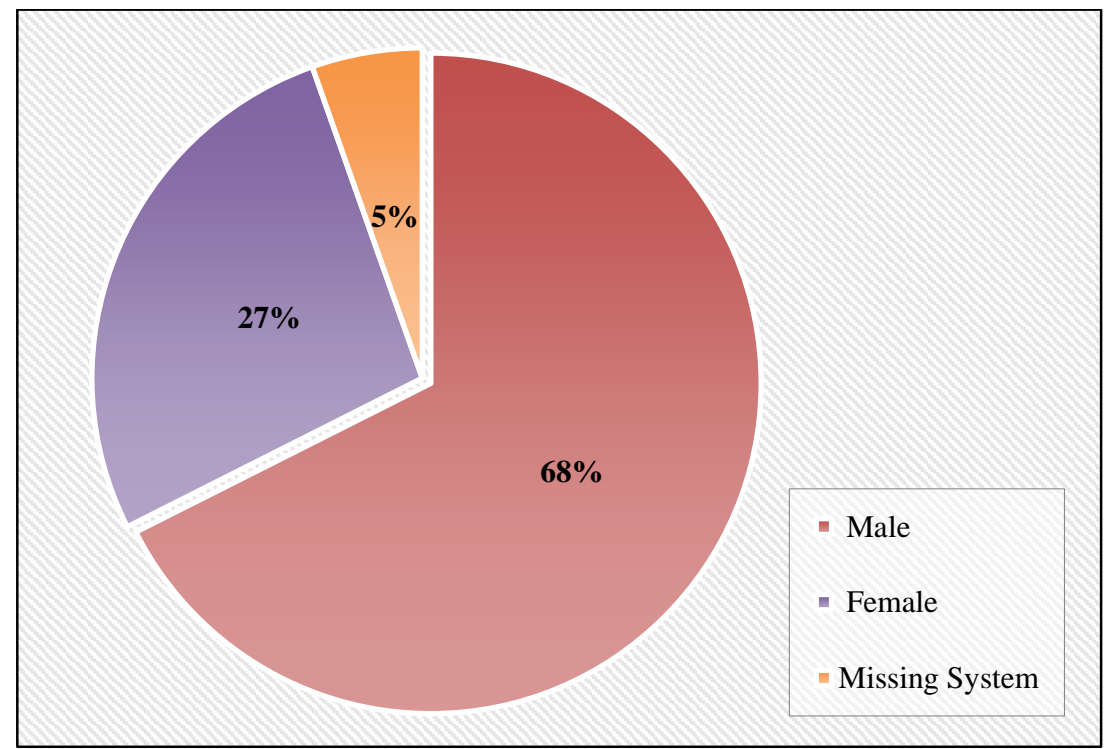

Figure 2. Gender of the respondent

The study findings revealed that $29.7 \%$ of the respondents were above 35 years, $24.3 \%$ of the respondents were between 21-25 years. $21.6 \%$ of the respondents were between 31-35 years, $13.5 \%$ was the non-response rate and finally $10.8 \%$ of the respondents were between 26-30 years. From the above findings, it was clearly found that most of the responses were from community members above 35years. The study findings revealed that Avitourism and biodiversity conservation was promoted and marketed mostly $(29.7 \%)$ by tour guides in the community who were at their prime age (35 years). Youths were the main promoters of Avitourism and biodiversity birds habitat conservation which resulted to popularity of Avitourism in the Kenya communities (Figure 3). 


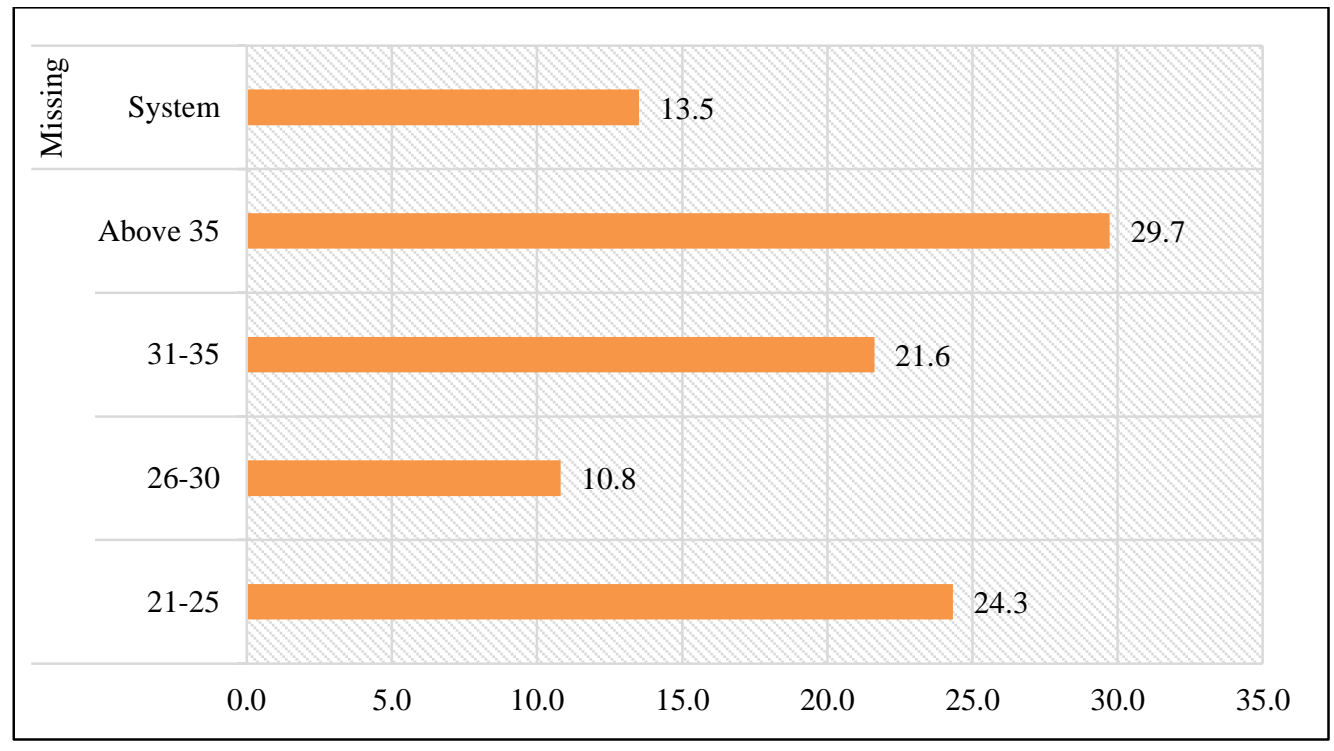

Figure 3. Age of the respondents in years $(\%)$

From the study findings it was indicate that most (54.1\%) of the community's members in Kenya had an education up to university level. Also $29.7 \%$ of the community's members in Kenya had an education up to middle level college. And finally, 5.4\% of the community's members in Kenya had an education up to secondary level and primary level respectively. The study findings also revealed that Avitourism and biodiversity conservation was highly promoted and popularized by learned and highly educated tour guides in the community who had their education up to the university level this was a good indication that Avitourism and biodiversity of birds habitat conservation was popular and constructive as productive and knowledgeable tour guides were involved in this study (Figure 4).

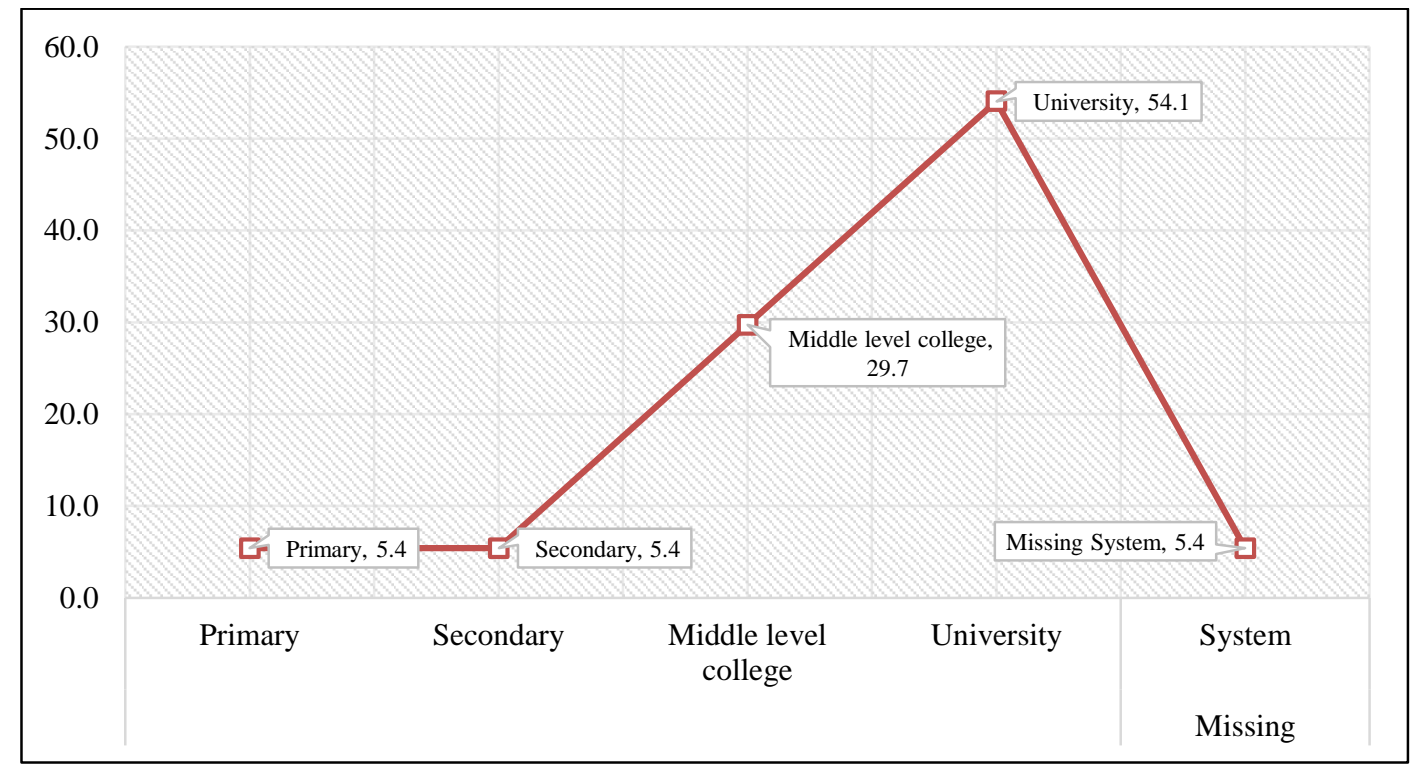

Figure 4. Education level (\%)

From the study findings, most of the responses (30\%) was from western community, $24 \%$ of the responses was from Nyanza community, $19 \%$ of the responses was from Coastal community, $16 \%$ of the responses was from Rift Valley community and finally $11 \%$ of the responses was from Maasai community. Avitourism and biodiversity of bird's conservation was highly promoted and popularized in Western community this was a good indication that Avitourism and biodiversity habitat conservation was popularized in Western community boosting their economical life aspects (Figure 5).

An analysis was performed and it was found out that, $59.9 \%$ of the community guide strongly considered birds to be very important to their community, $34.2 \%$ of the community guide considered birds to be very important to their community and $8.1 \%$ of the community guide strongly did not considered birds to be very important to their community. Moreover $13.9 \%$ of the community guide strongly considered that birds helped the community undertake rituals,52.8\% of the community guide considered that birds helped the community undertake rituals, $13.9 \%$ of the 
community guide strongly considered that birds helped the community undertake rituals, $22.2 \%$ of the community guide were neutral that birds helped the community undertake rituals, $8.3 \%$ of the community guide did not considered that birds helped the community undertake rituals and $2.8 \%$ of the community guide strongly did not considered that birds helped the community undertake rituals.

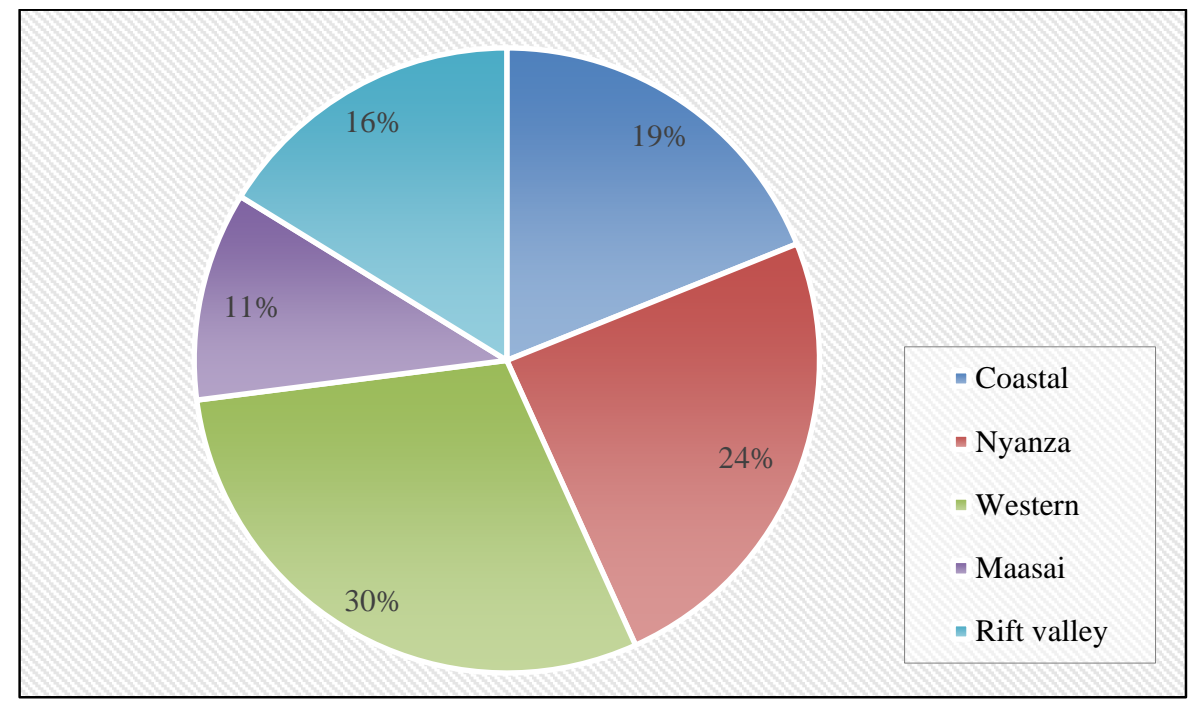

Figure 5. Respondent's community

Also $56.8 \%$ of the community guide strongly considered that birds helped the community tell when rain season was on undertake rituals, $35.1 \%$ of the community guide considered that birds helped the community tell when rain season is on undertake rituals, $5.4 \%$ of the community guide were neutral that birds helped the community tell when rain season is on undertake rituals and $2.7 \%$ of the community guide strongly did not considered that birds helped the community tell when rain season is on undertake rituals. $44.4 \%$ of the community guide strongly considered that birds guided the community when looking for specific items in the forest, $47.2 \%$ of the community guide considered that birds guided the community when looking for specific items in the forest and $8.3 \%$ of the community guide were neutral that birds guided the community when looking for specific items in the forest. However, $43.2 \%$ of the community guide strongly considered that birds warned community members against danger, $40.5 \%$ of the community guide considered that birds warned community members against danger, $8.3 \%$ of the community guide were neutral that birds warned community members against danger, $5.4 \%$ of the community guide did not consider that birds warned community members against danger and $2.7 \%$ of the community guide strongly did not consider that birds warned community members against danger.

Apparently $54.1 \%$ of the community guide strongly considered that birds helped the community spreading certain tree species, $43.2 \%$ of the community guide considered that birds helped the community spreading certain tree species and finally $2.7 \%$ of the community guide strongly did not consider that birds helped the community spreading certain tree species. On the other hand, the study findings revealed that Avitourism and biodiversity of bird's habitat conservation was highly promoted and popularized in Kenya communities as it was significant to them in dynamic ways such as telling when rain season was on undertake rituals, warning the community members against danger and spreading certain tree species (Table 1).

Table 1. Importance of birds in the community

\begin{tabular}{|c|c|c|c|c|c|c|}
\hline & Strongly Disagree & Disagree & Neutral & Agree & Strongly Agree & Total \\
\hline & Row N \% & Row N \% & Row N \% & Row N \% & Row N \% & Row N \% \\
\hline $\begin{array}{l}\text { I consider birds to be very important } \\
\text { to my community }\end{array}$ & $8.1 \%$ & $0.0 \%$ & $0.0 \%$ & $32.4 \%$ & $59.5 \%$ & $100.0 \%$ \\
\hline $\begin{array}{l}\text { Birds help the community undertake } \\
\text { rituals }\end{array}$ & $2.8 \%$ & $8.3 \%$ & $22.2 \%$ & $52.8 \%$ & $13.9 \%$ & $100.0 \%$ \\
\hline $\begin{array}{l}\text { Birds help the community tell when } \\
\text { rain season is on }\end{array}$ & $2.7 \%$ & $0.0 \%$ & $5.4 \%$ & $35.1 \%$ & $56.8 \%$ & $100.0 \%$ \\
\hline $\begin{array}{l}\text { Birds guide the community when } \\
\text { looking for specific items in the forest }\end{array}$ & $0.0 \%$ & $0.0 \%$ & $8.3 \%$ & $47.2 \%$ & $44.4 \%$ & $100.0 \%$ \\
\hline $\begin{array}{l}\text { Birds warn the community members } \\
\text { against danger }\end{array}$ & $2.7 \%$ & $5.4 \%$ & $8.1 \%$ & $40.5 \%$ & $43.2 \%$ & $100.0 \%$ \\
\hline $\begin{array}{l}\text { Birds help the community spreading } \\
\text { certain tree species }\end{array}$ & $2.7 \%$ & $0.0 \%$ & $0.0 \%$ & $43.2 \%$ & $54.1 \%$ & $100.0 \%$ \\
\hline
\end{tabular}


After the analysis, the findings revealed that, $29.7 \%$ of the community guide strongly considered some birds sacred, $43.2 \%$ of the community guide considered some birds sacred, $21.6 \%$ of the community guide were neutral that some birds sacred and $5.4 \%$ of the community guides did not consider some birds sacred. Also $32.4 \%$ of the community guides strongly considered birds shaped the community's social lives through stories and legends, 54.1\% of the community guides considered birds shaped the community's social lives through stories and legends, 5.4\% of the community guides were neutral that birds shaped the community's social lives through stories and legends and $8.1 \%$ of the community guides did not considered birds shaped the community's social lives through stories and legends.

Apparently $51.4 \%$ of the community guides strongly considered some birds as symbols for bad omen,40.5\% of the community guides considered some birds as symbols for bad omen, $2.7 \%$ of the community guides were neutral some birds as symbols for bad omen and $5.4 \%$ of the community guides strongly did not consider some birds as symbols for bad omen. On the other hand, $40.5 \%$ of the community guides strongly considered some birds are for good omen in the community, $48.6 \%$ of the community guides strongly considered some birds are for good omen in the community, $8.1 \%$ of the community guides were neutral that some birds are for good omen in the community and $2.7 \%$ of the community guides strongly did not consider some birds are for good omen in the community. $30.6 \%$ of the community guides strongly considered some birds for planting season in the community, $50.6 \%$ of the community guides considered some birds for planting season in the community, $16.7 \%$ of the community guides were neutral that some birds for planting season in the community and $2.8 \%$ of the community guides did not consider some birds for planting season in the community.

Moreover $24.3 \%$ of the community guides strongly considered some birds are a nuisance to the community, $54.1 \%$ of the community guides considered some birds are a nuisance to the community, $16.2 \%$ of the community guides were neutral some birds are a nuisance to the community, $2.7 \%$ of the community guides did not consider some birds are a nuisance to the community and finally $2.7 \%$ of the community guides strongly did not consider some birds are a nuisance to the community. The study findings also revealed that Avitourism and biodiversity of bird's habitat conservation was highly promoted and popularized in Kenya communities as it was important to them in different ways such as some birds were symbols for; bad omen also a nuisance to the community and this helped them in casting away the bad spell. Some birds for planting season in the community among others this attracted the Avitourism activities as well as biodiversity of birds habitat conservation (Table 2).

Table 2. Birds and habitat conservation

\begin{tabular}{|c|c|c|c|c|c|c|}
\hline & Strongly Disagree & Disagree & Neutral & Agree & Strongly Agree & Total \\
\hline & Row N \% & Row N \% & Row N \% & Row N \% & Row N \% & Row N \% \\
\hline I consider some birds sacred & $0.0 \%$ & $5.4 \%$ & $21.6 \%$ & $43.2 \%$ & $29.7 \%$ & $100.0 \%$ \\
\hline $\begin{array}{l}\text { Birds shape the community's social lives through } \\
\text { stories and legends }\end{array}$ & $0.0 \%$ & $8.1 \%$ & $5.4 \%$ & $54.1 \%$ & $32.4 \%$ & $100.0 \%$ \\
\hline $\begin{array}{l}\text { Some birds are considered as symbols for bad } \\
\text { omen }\end{array}$ & $5.4 \%$ & $0.0 \%$ & $2.7 \%$ & $40.5 \%$ & $51.4 \%$ & $100.0 \%$ \\
\hline Some birds are for good omen in the community & $2.7 \%$ & $0.0 \%$ & $8.1 \%$ & $48.6 \%$ & $40.5 \%$ & $100.0 \%$ \\
\hline Some birds for planting season in the community & $0.0 \%$ & $2.8 \%$ & $16.7 \%$ & $50.0 \%$ & $30.6 \%$ & $100.0 \%$ \\
\hline Some birds are a nuisance to the community & $2.7 \%$ & $2.7 \%$ & $16.2 \%$ & $54.1 \%$ & $24.3 \%$ & $100.0 \%$ \\
\hline
\end{tabular}

From the findings, it was indicated that, $27 \%$ of the community guides strongly considered birds would warn the community against danger, $62.2 \%$ of the community guides strongly considered birds would warn the community against danger, $8.1 \%$ of the community guides were neutral that birds would warn the community against danger and $2.7 \%$ of the community guides strongly did not considered birds would warn the community against danger, $29.7 \%$ of the community guides strongly considered they tell this story to tourists' bird as a guide, $59.5 \%$ of the community guides strongly considered they tell this story to tourists' bird as a guide and $10.8 \%$ of the community guides were neutral, they tell this story to tourists' bird as a guide. Also $48.6 \%$ of the community guides strongly considered birds are used to foretell events or weather, $40.5 \%$ of the community guides considered birds are used to foretell events or weather and $10.8 \%$ of the community guides were neutral that birds are used to foretell events or weather. Moreover $40.5 \%$ of the community guides strongly considered birds are used to determine how healthy the water systems are, $37.8 \%$ of the community guides considered birds are used to determine how healthy the water systems are, $16.2 \%$ of the community guides were neutral that birds are used to determine how healthy the water systems are and $5.4 \%$ of the community guides did not considered birds are used to determine how healthy the water systems are. However, $81.1 \%$ of the community guides strongly considered birds are good for tourism, $16.2 \%$ of the community guides considered birds are good for tourism and $2.7 \%$ of the community guides strongly did not considered birds are good for tourism, On the other hand $54.1 \%$ of the community guides strongly considered birds can sustain tourism, $35.1 \%$ of the community guides s considered birds can sustain tourism and finally $10.8 \%$ of the community guides were neutral that 
birds can sustain tourism. The study findings also indicated that Avitourism and biodiversity of bird's habitat conservation was promoted and popularized in Kenya communities as birds sustained tourism, birds was good for tourism, birds was used to determine how healthy the water systems and birds also warned the community against danger. These activities resulted to development of Avitourism industries and biodiversity of birds habitat conservation (Table 3).

Table 3. Birds and avitourism activity

\begin{tabular}{|c|c|c|c|c|c|c|}
\hline & Strongly Disagree & Disagree & Neutral & Agree & Strongly Agree & Total \\
\hline & Row $N \%$ & Row N \% & Row N \% & Row N \% & Row N \% & Row $N \%$ \\
\hline $\begin{array}{l}\text { Birds would warn the community against } \\
\text { danger }\end{array}$ & $2.7 \%$ & $0.0 \%$ & $8.1 \%$ & $62.2 \%$ & $27.0 \%$ & $100.0 \%$ \\
\hline As a guide I tell this story to tourists & $0.0 \%$ & $0.0 \%$ & $10.8 \%$ & $59.5 \%$ & $29.7 \%$ & $100.0 \%$ \\
\hline Birds are used to foretell events or weather & $0.0 \%$ & $0.0 \%$ & $10.8 \%$ & $40.5 \%$ & $48.6 \%$ & $100.0 \%$ \\
\hline $\begin{array}{l}\text { Birds are used to determine how healthy the } \\
\text { water systems are }\end{array}$ & $0.0 \%$ & $5.4 \%$ & $16.2 \%$ & $37.8 \%$ & $40.5 \%$ & $100.0 \%$ \\
\hline Birds are good for tourism & $2.7 \%$ & $0.0 \%$ & $0.0 \%$ & $16.2 \%$ & $81.1 \%$ & $100.0 \%$ \\
\hline Birds can sustain tourism & $0.0 \%$ & $0.0 \%$ & $10.8 \%$ & $35.1 \%$ & $54.1 \%$ & $100.0 \%$ \\
\hline
\end{tabular}

After the analysis, the findings indicated that, $54.1 \%$ of the community guides strongly considered birds can help them earn money, $40.5 \%$ of the community guides considered birds can help them earn money, $2.7 \%$ of the community guides were neutral that birds can help them earn money, and $2.7 \%$ of the community guides strongly did not considered birds can help them earn money. $48.6 \%$ of the community guides strongly considered birds can help them improve their livelihood, $40.5 \%$ of the community guides considered birds can help them improve their livelihood, $8.1 \%$ of the community guides were neutral that birds can help them improve their livelihood and $2.7 \%$ of the community guides strongly did not considered birds can help them improve their livelihood. $35.1 \%$ of the community guides strongly considered birds can helped start and sustain cottage industries, $45.9 \%$ of the community guides considered birds can helped start and sustain cottage industries, $16.2 \%$ of the community guides were neutral that birds can helped start and sustain cottage industries and $2.7 \%$ of the community guides did not considered birds can helped start and sustain cottage industries.

On the other hand $64.9 \%$ of the community guides strongly considered birds was important to them through pollen transfer, $32.4 \%$ of the community guides considered birds was important to them through pollen transfer and $2.7 \%$ of the community guides strongly did not considered birds was important to them through pollen transfer. However, $54.1 \%$ of the community guides strongly considered that they benefit from birds in the forest through tourism and $45.9 \%$ of the community guides considered that they benefit from birds in the forest through tourism. Also $35.1 \%$ of the community guides strongly considered birds guided them to locate nesting bees for honey collection, $54.1 \%$ of the community guides considered birds guided them to locate nesting bees for honey collection, $8.1 \%$ of the community guides were neutral that birds guided them to locate nesting bees for honey collection and finally $2.7 \%$ of the community guides did not considered birds guided them to locate nesting bees for honey collection. The study findings also indicated that Avitourism and biodiversity of bird's habitat conservation was promoted and popularized in Kenya communities as birds helped them; earn money, improved their livelihood, start and sustained cottage industries and guided them to locate nesting bees for honey collection (Table 4).

Table 4. Contribution of birds on community livelihoods

\begin{tabular}{|c|c|c|c|c|c|c|}
\hline & Strongly Disagree & Disagree & Neutral & Agree & Strongly Agree & Total \\
\hline & Row N \% & Row N \% & Row N \% & Row N \% & Row N \% & Row N \% \\
\hline Birds can help me earn money & $2.7 \%$ & $0.0 \%$ & $2.7 \%$ & $40.5 \%$ & $54.1 \%$ & $100.0 \%$ \\
\hline Birds can help me improve my livelihood & $2.7 \%$ & $0.0 \%$ & $8.1 \%$ & $40.5 \%$ & $48.6 \%$ & $100.0 \%$ \\
\hline $\begin{array}{l}\text { Birds can help start and sustain cottage } \\
\text { industries }\end{array}$ & $0.0 \%$ & $2.7 \%$ & $16.2 \%$ & $45.9 \%$ & $35.1 \%$ & $100.0 \%$ \\
\hline $\begin{array}{l}\text { Birds are important to us through pollen } \\
\text { transfer }\end{array}$ & $2.7 \%$ & $0.0 \%$ & $0.0 \%$ & $32.4 \%$ & $64.9 \%$ & $100.0 \%$ \\
\hline $\begin{array}{l}\text { We benefit from birds in the forest through } \\
\text { tourism }\end{array}$ & $0.0 \%$ & $0.0 \%$ & $0.0 \%$ & $45.9 \%$ & $54.1 \%$ & $100.0 \%$ \\
\hline $\begin{array}{l}\text { Birds guide us to locate nesting bees for honey } \\
\text { collection }\end{array}$ & $0.0 \%$ & $2.7 \%$ & $8.1 \%$ & $54.1 \%$ & $35.1 \%$ & $100.0 \%$ \\
\hline
\end{tabular}

The study findings revealed that, $40.5 \%$ of the community guides strongly considered birds guided them to locate fruits in the forest, $40.5 \%$ of the community guides considered birds guided them to locate fruits in the forest, $16.2 \%$ of the community guides were neutral that birds guided them to locate fruits in the forest and $2.7 \%$ of the community 
guides strongly did not considered birds guided them to locate fruits in the forest. Also $21.6 \%$ of the community guides strongly considered birds was celebrated in their community, $40.5 \%$ of the community guides considered birds was celebrated in their community, $27.9 \%$ of the community guides were neutral that birds were celebrated in their community and $8.1 \%$ of the community guides did not considered birds was celebrated in their community. Also $37.8 \%$ of the community guides strongly considered birds gave them happiness, $48.6 \%$ of the community guides considered birds gave them happiness, $10.8 \%$ of the community guides were neutral that birds gave them happiness and $2.7 \%$ of the community guides strongly did not considered birds gave them happiness.

On the other hand, $51.4 \%$ of the community guides strongly considered that as a guide they were involved in bird's conservation, $35.1 \%$ of the community guides considered that as a guide they were involved in bird's conservation, $10.8 \%$ of the community guides were neutral that as a guide they are involved in bird's conservation and $2.7 \%$ of the community guides strongly did not consider that as a guide they were involved in bird's conservation. Apparently $56.8 \%$ of the community guides strongly considered that as a guide they were involved in bird's habitat conservation, $27 \%$ of the community guides strongly considered that as a guide they were involved in bird's habitat conservation, $13.5 \%$ of the community guides strongly considered that as a guide they were involved in bird's habitat conservation and finally $2.7 \%$ of the community guides strongly did not consider that as a guide they were involved in bird's habitat conservation. The study findings also indicated that Avitourism and biodiversity of bird's habitat conservation was promoted and popularized in Kenya communities as birds; guided them to locate fruits in the forest, were celebrated in their community and the community tour guides were also involved in bird's habitat conservation (Table 5).

Table 5. Avitourism guides and birds

\begin{tabular}{|c|c|c|c|c|c|c|}
\hline & Strongly Disagree & Disagree & Neutral & Agree & Strongly Agree & Total \\
\hline & Row N \% & Row N \% & Row N \% & Row N \% & Row N \% & Row N \% \\
\hline Birds guide us to locate fruits in the forest & $2.7 \%$ & $0.0 \%$ & $16.2 \%$ & $40.5 \%$ & $40.5 \%$ & $100.0 \%$ \\
\hline Birds are celebrated in our community & $0.0 \%$ & $8.1 \%$ & $29.7 \%$ & $40.5 \%$ & $21.6 \%$ & $100.0 \%$ \\
\hline Birds give us happiness & $2.7 \%$ & $0.0 \%$ & $10.8 \%$ & $48.6 \%$ & $37.8 \%$ & $100.0 \%$ \\
\hline As a guide I am involved in bird's conservation & $2.7 \%$ & $0.0 \%$ & $10.8 \%$ & $35.1 \%$ & $51.4 \%$ & $100.0 \%$ \\
\hline As a guide I am involved in bird's habitat conservation & $2.7 \%$ & $0.0 \%$ & $13.5 \%$ & $27.0 \%$ & $56.8 \%$ & $100.0 \%$ \\
\hline
\end{tabular}

\section{Discussion}

The study found that a total of $29.7 \%$ of the respondents were above 35 years, most of the respondents were male $(68 \%)$. Majority of the community guides had their education up to university level that is $54.1 \%$ and most respondents $(30 \%)$ were from western community. The study found that the community guides strongly considered that as a guide they were involved in bird's habitat conservation, the community guides strongly considered that as a guide they were involved in bird's conservation, the community guides considered birds was celebrated in their community, the community guides considered birds gave them happiness, the community guides considered birds can helped start and sustain cottage industries, the community guides strongly considered birds was important to them through pollen transfer, the community guides strongly considered that they benefit from birds in the forest through tourism, the community guides considered birds guided them to locate nesting bees for honey collection, the community guides strongly considered birds guided them to locate fruits in the forest, the community guides considered birds guided them to locate fruits in the forest,

The community guides strongly considered birds would warn the community against danger, the community guides strongly considered they tell this story to tourists' bird as a guide the community guides strongly considered birds are used to foretell events or weather, the community guides strongly considered birds are used to determine how healthy the water systems are, the community guides strongly considered birds are good for tourism, the community guides strongly considered birds can sustain tourism, the community guides strongly considered birds can help them earn money, the community guides strongly considered birds can help them improve their livelihood,

The community guides considered some birds for planting season in the community, the community guides considered some birds are a nuisance to the community, the community guide strongly considered that birds warned community members against danger, the community guide strongly considered that birds helped the community spreading certain tree species, the community guide considered some birds sacred, the community guides considered birds shaped the community's social lives through stories and legends, community guides strongly considered some birds as symbols for bad omen, community guides strongly considered some birds are for good omen in the community, community guide strongly considered birds to be very important to their community, community guide considered that birds helped the community undertake rituals, community guide were neutral that birds helped the community undertake rituals, community guide strongly considered that birds helped the community tell when rain season is on undertake rituals. 


\subsection{Strengths and Limitations}

The strength of the study lies in being a community-based study with a considerably high participation rate. Also, this is probably amongst the few studies among community guides' beliefs attached to different birds in Kenya. The study had its limitations too. Primary-data, took time and efforts to obtain outlooks from 37 respondents at Maasai, Western, Rift valley, Nyanza and Coastal communities. Time limitations, was the major challenges, to submit the whole research on time.

The present study focused on community guided beliefs attached to different birds in Kenya, and the scale used did not consider other aspects which probably have a bearing on birds' beliefs. Therefore, these aspects would need to be explored more, along with the dynamics of intra-familial birds' beliefs. The sample size was calculated considering a non-response rate, but during the data collection, the non-response rate was present. This might reduce the precision of the findings. Also, the primary reason for non-response was that the respondents were preoccupied with community guide work.

\subsection{Community Guides Roles in Avitourism and Conservation}

This study findings, revealed very important and critical roles performed by community guides in five provinces (Western, Nyanza, Mombasa, Narok and Rift Valley) of Kenya was a measure of Avitourism and conservation practices by conserving and protecting birds which in turn benefitted them in numerous ways in terms of; undertaking rituals with the help of birds, under the guidance of birds the community members were able to locate specific items in the forest. On the other hand, birds also warned community members against danger, guided them while locating fruits in the forest, were celebrated in their community, and the community tour guides were also involved in bird's habitat conservation, earning money, improving their livelihood, starting and sustaining cottage industries, and guiding them to locate nesting bees for honey collection. Furthermore, aligned with the international trend, conservationists have become more aware of the critical need to ensure benefits to and the inclusive participation of local communities in conservation (Brooks \& Thompson (2001) [21]; Berkes (2004) [22]; Sanderson et al. (2005) [23]). The only quantitative study to date on avitourism to South Africa conservatively estimated that by 1997, between 11,400 and 21,200 birdwatchers spent USD 12-26 million annually in the South African economy [24]. Similarly, in Kenya, as evidenced in South Africa by Turpie \& Ryan (1998) [24], birdwatchers spent a huge amount of money annually, boosting the Kenyan economy to drastically grow besides creating employment for Kenyans in the tourism, hospitality, and hotel management sectors.

\section{Conclusion}

This study explored the community guides beliefs attached to different birds in Kenya. Themes emerged from the data, and indicated that the community guide beliefs attached to different birds in Kenya were primarily viewed as an omen or signifier of death, loss, and destruction, as a protective influence, as an enabler of altered perceptions and remote viewing, and as a timekeeper in relation to seasonal and daily changes.

\section{Declarations}

\subsection{Data Availability Statement}

The data presented in this study are available in article.

\subsection{Funding}

The author received no financial support for the research, authorship, and/or publication of this article.

\subsection{Institutional Review Board Statement}

Not applicable.

\subsection{Informed Consent Statement}

All the study participants signed an informed consent agreeing to provide data and availability for the survey.

\subsection{Declaration of Competing Interest}

The author declare that there is no conflict of interests regarding the publication of this manuscript. In addition, the ethical issues, including plagiarism, informed consent, misconduct, data fabrication and/or falsification, double publication and/or submission, and redundancies have been completely observed by the author. 


\section{References}

[1] Collar, N., Long, A. J., Gil, P. R., \& Rojo, J. (2007). Birds and People. Bonds in a Timeless Journey. Cemex-Agrupacion Sierra Madre-BirdLife International, Mexico.

[2] Xu, Y., Si, Y., Takekawa, J., Liu, Q., Prins, H. H. T., Yin, S., Boer, W. F. (2019). A network approach to prioritize conservation efforts for migratory birds. Conservation Biology, 34(2), 416-426. doi:10.1111/cobi.13383.

[3] Meyer-Rochow, V. B. (2009). Food taboos: their origins and purposes. Journal of Ethnobiology and Ethnomedicine, 5(1), 1-10. doi:10.1186/1746-4269-5-18.

[4] Mkhize, N. (2008). Psychology: An African perspective. In Hook, D., Mkhize, N., Kiguwa, P., Collins, A. (Eds.), Critical psychology (pp. 24-52). University of Cape Town Press.

[5] Fernandes-Ferreira, H., Mendonça, S. V., Albano, C., Ferreira, F. S., \& Alves, R. R. N. (2011). Hunting, use and conservation of birds in Northeast Brazil. Biodiversity and Conservation, 21(1), 221-244. doi:10.1007/s10531-011-0179-9.

[6] Alves, R. R. N., Rosa, I. L., Léo Neto, N. A., \& Voeks, R. (2012). Animals for the Gods: Magical and Religious Faunal Use and Trade in Brazil. Human Ecology, 40(5), 751-780. doi:10.1007/s10745-012-9516-1.

[7] Derwent, S., \& Mander, M. (1997). Twitchers bewitched. The use of birds in traditional healing. Africa: Birds \& Birding, 2(1), $22-25$.

[8] Ng'weno, F. (2012). Sound, Sight, Stories and Science: Avoiding Methodological Pitfalls in Ethno-Ornithological Research, with Examples from Kenya. In Ethno-Ornithology: Birds, Indigenous People, Cultures and Society. Edited by Tidemann S, Gosler A. Washington: Earthscan; Pp. (103-113) Routledge.

[9] Setha, T. (2004). The status and conservation of hornbills in Cambodia. Bird Conservation International, 14(S1), S5-S11. doi:10.1017/s0959270905000183.

[10] Kalimira, N., Kemp, A. C., \& Kemp, M. I. (2007). The status of the Southern Ground Hornbill Bucorvus leadbeateri in some protected areas of Malawi. The Active Management of Hornbills and their Habitats for Conservation: 4-9 November 2005, 245-251.

[11] Makinde, O. O. (2020). The Effects of Physical and Social Characteristics on Residents' Perception on Neighbourhood Quality in the Urban Environment. Journal of Human, Earth, and Future, 1(3), 122-145.

[12] Simelane T.S., Knight M.G., (1977) Traditional beliefs and conservation. Custos, Tanzania: The Case for MalagarasiMoyovoza Ramsar Site. In the Active Management of Hornbills and their Habitats for Conservation: 4-9 November 2005, Bela Bela. Edited by Kemp AC, Kemp MI. Pretoria: Naturalists \& Nomads; (2007):240-244.

[13] Alves, R. (2012). Relationships between fauna and people and the role of ethnozoology in animal conservation. Ethnobiology and Conservation. doi:10.15451/ec2012-8-1.2-1-69.

[14] Coetzee, H., Nell, W., \& van Rensburg, L. (2014). An exploration of cultural beliefs and practices across the Southern Ground-Hornbill's range in Africa. Journal of Ethnobiology and Ethnomedicine, 10(1). doi:10.1186/1746-4269-10-28

[15] Tidemann, S., \& Gosler, A. (2010). Ethno-ornithology: birds, indigenous people, culture and society. London/Washington: Earthscan, Edited by Tidemann S, Gosler A. Washington: Earthscan; 279-289.

[16] Kemp, A. C. (1995). The hornbills: bucerotiformes. Oxford, United Kingdom.

[17] Kemp, AC \& Kemp, M. I. (1980). The biology of the southern ground hornbill Bucorvus leadbeateri (Vigors) (Aves: Bucerotidae). Annals of the Transvaal Museum, 32(4), 65-100.

[18] Theron, N. T. (2011). Genetic connectivity, population dynamics and habitat selection of the Southern ground hornbill (Bucorvus leadbeateri) in the Limpopo Province, Ph.D. Dissertation, University of the Free State, Bloemfontein, South Africa.

[19] Sidney Shema, (2020). Kenya Bird Map Blog: A blog for sharing information, updates and tips relating to the Kenya Bird Map project. Avalible online: https://kenyabirdmap.wordpress.com/ (accessed on May 2020).

[20] Taylor, L. A., Biro, D., Lambert, B., Walker, J. A., Taylor, G. K., \& Portugal, S. J. (2018). Birds invest wingbeats to keep a steady head and reap the ultimate benefits of flocking. doi:10.1101/492090.

[21] Brooks, Thomas, and Hazell Shokellu Thompson. "Current Bird Conservation Issues in Africa." The Auk 118, No. 3 (July 1, 2001): 575-582. doi:10.1093/auk/118.3.575.

[22] Berkes, F. (2004). Rethinking Community-Based Conservation. Conservation Biology, 18(3), 621-630. doi:10.1111/j.15231739.2004.00077.x.

[23] Sanderson, F. J. , Donald, P. F. , \& Burfield, I. J. (2005). Farmland birds in Europe: From policy change to population decline and back again. In Bota G., Morales M. B., Mañosa S., \& Camprodon J. (Eds.), Ecology and conservation of steppe-land birds (pp. 211-236). Lynx Edicions.

[24] Turpie, J. K., \& Ryan, P. G. (1998). The nature and value of birding in South Africa. BirdLife South Africa Research Series, 1, $1-41$. 